\title{
Wideband Dual-Arm Capacitively Coupled Patch Antenna for Tablet/Laptop Applications
}

\author{
Sorana NIYAMANON, Pisit JANPANGNGERN, Chuwong PHONGCHAROENPANICH \\ Faculty of Engineering, King Mongkut's Institute of Technology Ladkrabang, Bangkok 10520, Thailand \\ chuwong.ph@kmitl.ac.th
}

Submitted March 20, 2018 / Accepted August 16, 2019

\begin{abstract}
The capacitively coupled microstrip antenna for $4 \mathrm{G}$ and $\mathrm{Wi}-\mathrm{Fi}$ applications is presented. The antenna has a compact size which can easily be installed into many types of wireless communication device. The antenna is designed on FR4 substrate with a total dimension of $70 \mathrm{~mm} \times 9 \mathrm{~mm} \times 0.8 \mathrm{~mm}$. The structure of the antenna consists of two main parts. The T-shape feeding patch located between two radiating strips with the ground strip being placed behind them. The surface current distribution and parametric study was analyzed to determine the suitable parameters. Furthermore, the antenna prototype was fabricated and tested. The operating frequency range of the proposed antenna is between $1.7 \mathrm{GHz}$ and $2.5 \mathrm{GHz}$ for the $\left|S_{11}\right|$ of less than $-10 \mathrm{~dB}$. The antenna provides a linear polarization in a single beam direction covering approximately one quadrant of the free space with a maximum gain of higher than $1.47 \mathrm{dBi}$ on the entire frequency band.
\end{abstract}

\section{Keywords}

Capacitively coupled, tablet/laptop, wideband, 4G and Wi-Fi applications

\section{Introduction}

Nowadays, wireless communication technology plays an important role in a part of people daily life. Since each type of wireless application is operated on different frequency ranges, a modern wireless communication device must be able to provide an operation on those many frequency bands. This leads to designs of wide band antenna using various bandwidth enhancement techniques. For example, coplanar waveguide CPW-fed slot antenna [1] enhances its bandwidth via an asymmetrical slot. This results in the antenna having $82 \%$ impedance bandwidth. Nevertheless, this antenna has a low gain of less than $1 \mathrm{dBi}$ at some operating frequencies. Another important aspect of handheld wireless devices is a compact size. Therefore, the antenna must be small enough in order to be implemented inside the limited available space inside those devices. This results in invention of compact antenna [2-7]. In [2-5], the development of the Digital Video Broadcasting to a Hand- held (DVB-H) standard has made it possible to deliver live broadcast television to a mobile handheld device. To satisfy the rapidly growing demands, an antenna should be responsive in many frequency bands. Many different types of multi-band antennas with digital television (DTV) operation have been proposed over the years. However, they tend to have a problem of interference among the operating frequencies for installation in a limited space. The antenna in [6], [7] introduces the lump elements into the antenna structure in order to improve the impedance matching. Therefore the antenna having a small size could achieve an acceptable bandwidth. However, most antennas designed for portable device such as mobile phone or tablet take the device ground plane into an account. Thus, they cannot operate without the corresponding device structure attached. Literatures [8-13] present the broadband slot antennas. As reported in [8], [9], the complicated feeding network and L-shaped horizontal and vertical tuning stubs are used. Moreover, other proposed slot antennas, such as in [10], [11], with the fractal slot and the 3-D slot loop respectively, have been demonstrated. Also, some slot antennas with hybrid slots [12], [13] have been presented for broadband operation. However, those designs of proposed broadband slot antenna have complicated configurations that lead to a high complexity level regarding to the fabrication process. The antenna in [14] exhibits an original novel compact low-profile directional UWB antenna: the self-grounded bow-tie antenna. The antenna has a simple geometry, ultra-wideband performance with about $-10 \mathrm{~dB}$ reflection coefficient, stable radiation beams for the frequency range of $2 \mathrm{GHz}$ to $15 \mathrm{GHz}$, and good timedomain impulse response. In addition, bow-tie dipoles [15-18] and log-periodic dipoles [19], [20] were proposed for ultra-wideband applications. However, these antennas provide too wide impedance bandwidth that may bring other electromagnetic interferences.

This research paper presents an antenna that can operate on its own, which can be implemented inside any device that does not have a large ground structure. The antenna has a compact size which can easily be installed into many types of wireless communication device. The operating frequency range of the proposed antenna is between $1.7 \mathrm{GHz}$ and $2.5 \mathrm{GHz}$. The antenna provides a linear polarization with an unidirectional radiation pattern cov- 
ering approximately one quadrant of the free space with a gain of higher than $2.73 \mathrm{dBi}$ on the entire frequency band.

The organization of the research is as follows: Section 1 is the introduction. Section 2 describes the antenna design and parametric studies. Section 3 proposes the capacitively coupled patch antenna, and Section 4 discusses the antenna prototype and experimental results. Section 5 is the conclusion.

\section{Antenna Design and Parametric Studies}

\subsection{Single-Arm Capacitively Coupled Patch Antenna}

Figure 1 shows the structure of single-arm capacitively coupled patch antenna. The antenna is designed using an FR4 with a thickness of $0.8 \mathrm{~mm}$ as a substrate. The smallest conductor plane on the top right of Fig. 1 is a feeding patch with a size $\left(F \times W_{1}\right)$ of $2 \mathrm{~mm} \times 4 \mathrm{~mm}$. This feeding patch is directly connected to a $50 \Omega$ transmission line at point $A$ and couples the RF signal through a capacitive gap $(G=0.5 \mathrm{~mm})$ toward the radiating component with a dimension of $L \times W_{1}$ located next to it. There is a thin ground strip $\left(W_{\mathrm{g}}=1 \mathrm{~mm}\right)$ at the bottom of Fig. 1 which connected to ground of the $50 \Omega$ transmission line at point $B$.

The antenna is designed using folded dipole as a fundamental structure. Therefore, the first design of the antenna has a total length of approximately one fourth of the corresponding wavelength. The capacitive gap near the

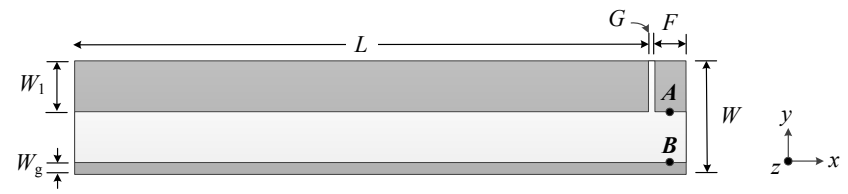

Fig. 1. Structure of single-arm capacitively coupled patch antenna.

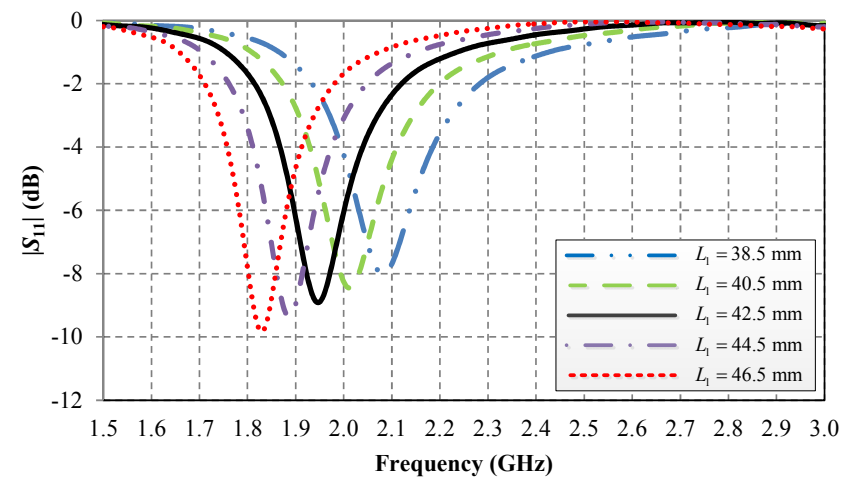

Fig. 2. Structure of single-arm capacitively coupled patch antenna. feeding point was added in order to introduce phase shifting into the radiating arm which improves the radiating efficiency of the antenna. Moreover, the suitable gap width also cancels out the inductance between two strip lines. This results in better refection coefficient of the antenna in the interested frequency range.

Figure 2 shows $\left|S_{11}\right|$ of the single-arm capacitively coupled patch antenna when the length of radiating arm $(L)$ is varied. It can be seen that the resonance frequency of the designed antenna is influenced by the length of radiating arm.

Since this single arm antenna structure only has one resonance frequency, bandwidth enhancement is needed. Therefore another radiating component is added in order to introduce an additional resonance frequency for this antenna design. This leads to a design of dual-arm capacitively coupled patch antenna which will be discussed in the next section.

\subsection{Dual-Arm Capacitively Coupled Patch Antenna}

The structure of dual-arm capacitively coupled patch antenna is shown in Fig. 3. The antenna is also designed using FR4 with a thickness of $0.8 \mathrm{~mm}$ as a substrate. However, there is another capacitively coupled radiating strip attached on the other side of the previous design. This results in two radiating strips using common ground and feeding structure. The additional arm has a different length $\left(L_{2}\right)$ compared with the original arm creating new resonance frequency for the patch antenna.

Figure 4 presents the reflection coefficient of the dual arm antenna with the radiating arms' length of $L_{1}=36 \mathrm{~mm}$ and $L_{2}=50 \mathrm{~mm}$. It can be clearly seen that there is an additional frequency band compared to this of the single arm antenna. As a result, the bandwidth of capacitively coupled antenna can be significantly enhanced. However, this bandwidth enhancement also comes with a huge increase in size of the antenna.

Figures 5(a) and 5(b) show $\left|S_{11}\right|$ of the dual-arm capacitively coupled antenna when each arm length $\left(L_{1}\right.$ and $L_{2}$ ) is varied. It can be seen that the change in length of the shorter arm directly affect the resonance frequency at the high frequency band while the lower resonance frequency almost remain unchanged. It can also be seen that the change in length of the longer arm almost only has an effect on the resonance frequency at lower band.

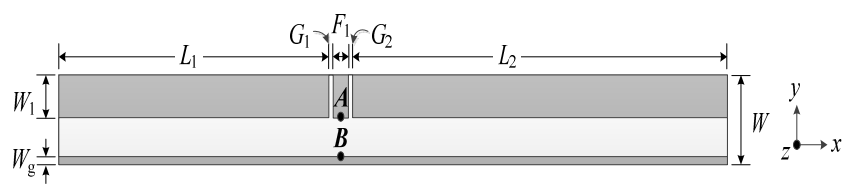

Fig. 3. Structure of single-arm capacitively coupled patch antenna. 


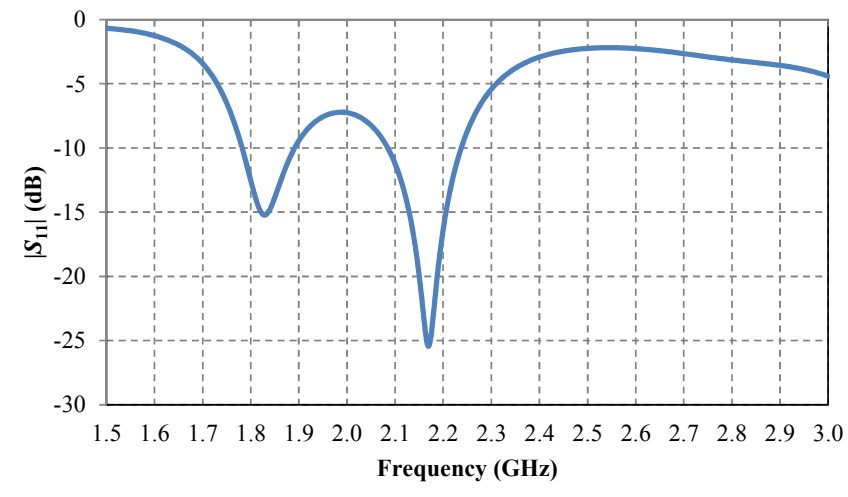

Fig. 4. $\left|S_{11}\right|$ of the dual arm antenna with a radiating arm length of $L_{1}=36 \mathrm{~mm}$ and $L_{2}=50 \mathrm{~mm}$.

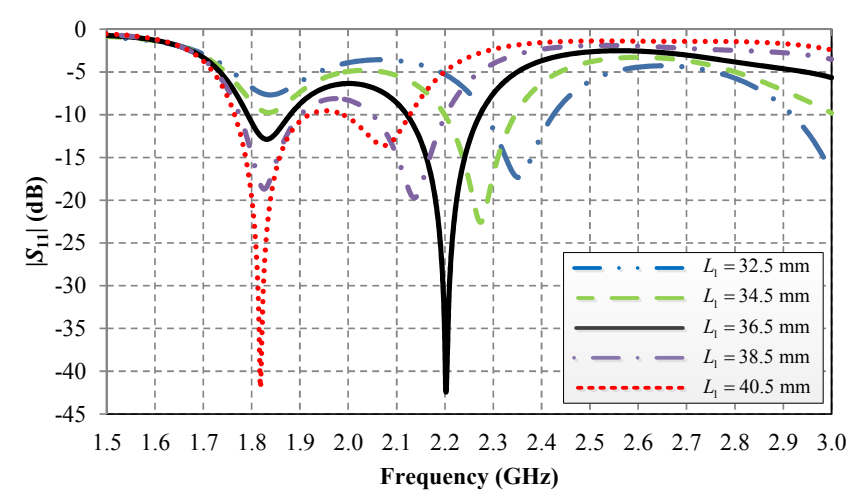

(a)

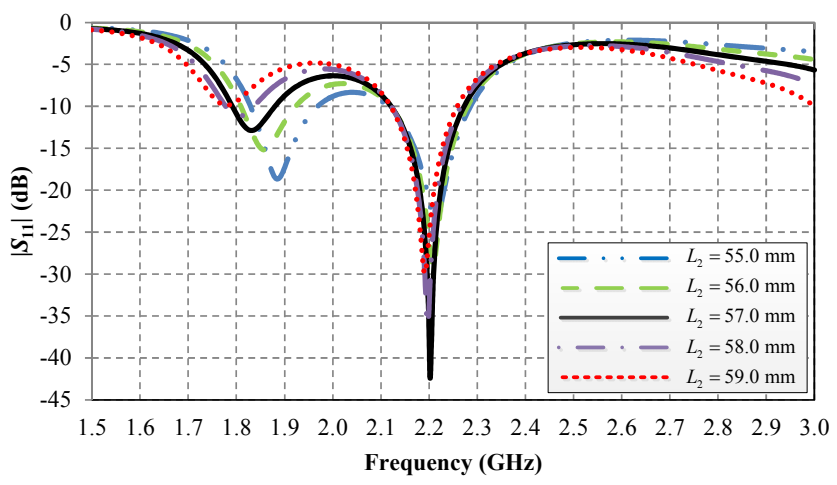

(b)

Fig. 5. $\left|S_{11}\right|$ of the dual-arm capacitively coupled patch antenna when (a) $L_{1}$ is varied, (b) $L_{2}$ is varied.

In addition, Figures 5(a) and 5(b) also show that the downward slope of those two independent resonance frequencies can be added up constructively when two radiating arm lengths are set properly. This results in further enhancement in frequency bandwidth at both resonance frequencies.

Although the antenna presented in Sec. 2.2 has a higher frequency bandwidth from $1.74 \mathrm{GHz}$ to $2.35 \mathrm{GHz}$ compared with the previous design, the antenna still cannot be operated in both 4G LTE $1700 \mathrm{MHz}$ band $(1.71 \mathrm{GHz}$ to $2.17 \mathrm{GHz})$ and $\mathrm{Wi}-\mathrm{Fi}$ band $(2.4 \mathrm{GHz}$ to $2.485 \mathrm{GHz})$. Therefore, other bandwidth enhancement technique is required so that the antenna bandwidth could cover both the entire 4G LTE and Wi-Fi band which will be presented in the next section.

\subsection{Elbow Capacitive Gap Structure}

Figure 6 shows the antenna with an elbow capacitive gap structure. There is some portion of the feeding patch extended toward the radiating component which the length of $F_{2}$. The change in coupling gap structure affects the impedance of the antenna which could result in an improvement in antenna bandwidth.

Figure 7(a) illustrates antenna resistance when the length of an extended feeding patch $\left(F_{2}\right)$ is varied. It can be seen that the resistance of antenna goes up as the feeding patch extended. Since current flows along the strip line direction, the extended feeding patch makes the area of the conducting line become smaller which lead to an increase in resistance.

Figure 7(b) shows antenna impedance when the length of an extended feeding patch $\left(F_{2}\right)$ is varied. As can be seen, the resonance frequency of the antenna shifted downward when the length $F_{2}$ increased. The total length of the capacitive gap becoming wider leads to an increasing in capacitance $(\mathrm{C})$. As a result, $-\mathrm{j} / \omega C$ becomes larger and the resonance frequency decreases.

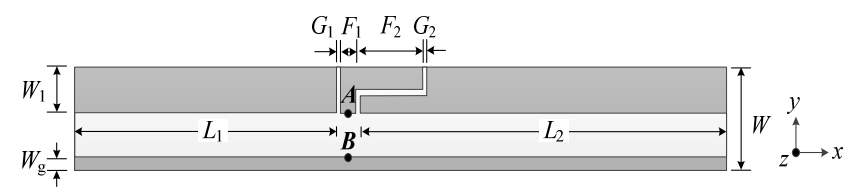

Fig. 6. Structure of dual-arm capacitively coupled patch antenna with an elbow capacitive gap structure.

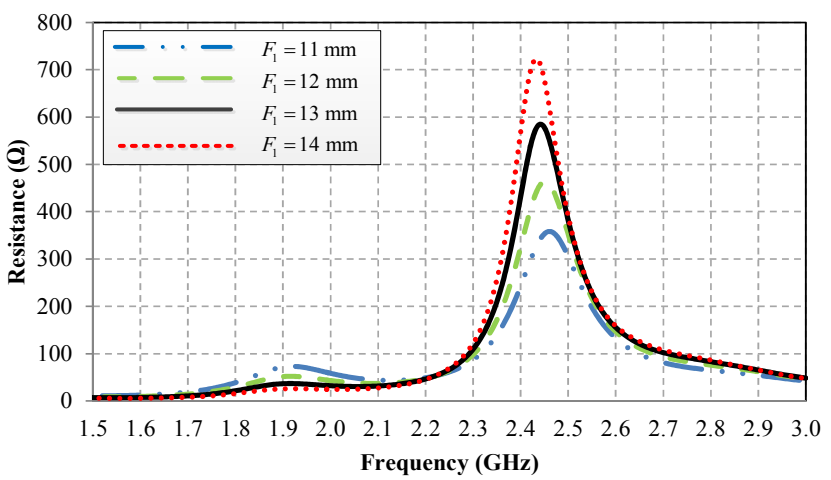

(a)

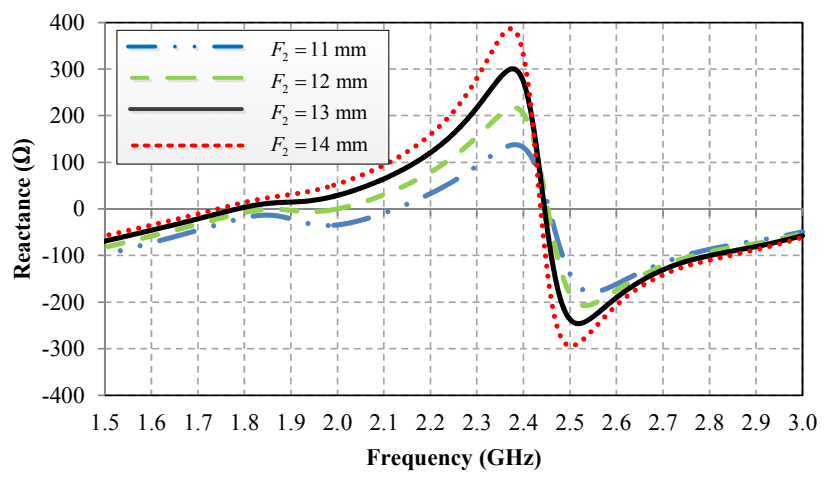

(b)

Fig. 7. Impedance of dual-arm capacitively coupled patch antenna when $F_{2}$ is varied: (a) Resistance. (b) Reactance. 


\section{Proposed Capacitively Coupled Patch Antenna}

The parametric study on the previous section leads to the optimized design of the antenna operating in $4 \mathrm{G}$ and Wi-Fi frequency bands.

Figure 8 illustrates the structure of the proposed antenna. The antenna is fabricated on FR4 substrate with a total dimension of $70 \mathrm{~mm} \times 9 \mathrm{~mm} \times 0.8 \mathrm{~mm}$. The T-shape feeding patch with a size of $F=6 \mathrm{~mm}, F_{1}=F_{2}=$ $9 \mathrm{~mm}$, and $C_{1}=C_{2}=2 \mathrm{~mm}$ is located between two radiating strips with gaps of $G_{1}=G_{2}=0.5 \mathrm{~mm}$. The radiating strips has a dimension of $L_{1} \times W_{1}=36 \mathrm{~mm} \times 4 \mathrm{~mm}$ and $L_{2} \times W_{2}=22 \mathrm{~mm} \times 4 \mathrm{~mm}$. There is a ground strip with a width of $1 \mathrm{~mm}$ behind the feeding patch and radiating strips with a gap between feeding patch and ground strip of $G_{3}=3 \mathrm{~mm}$.

When transmission line is connected to the feeding patch at point $A$ and ground is connected to the ground strip at point $B$, the RF signal will be coupled from the feeding patch to the corresponding radiating strip. The optimized capacitive gaps are designed to maximize the bandwidth of the proposed antenna. The capacitive gaps are also one of the size reduction methods which result in the radiating strips having a length of $0.288 \lambda$ and $0.139 \lambda$ for the corresponding $1.7 \mathrm{GHz}$ and $2.45 \mathrm{GHz}$. Therefore, the proposed antenna has an electrical size of $0.5 \lambda_{\text {min }}$.

\subsection{Surface Current Distribution}

The current distribution of the proposed antenna is depicted in Fig. 9. It can be seen that the current density changes according to the operating frequency. The ground strip remains active on the entire band, since it is the common component of the antenna structure. The current flows toward the right side of the antenna at high frequency and begins to spread toward the left side as the frequency decreases, because the short radiating strip resonates with higher frequency signal (short wavelength) and the long one resonates with lower frequency signal (long wavelength). The current mostly flows along the strip lines. Thus, linearly polarized characteristic should be expected.

Figure 9(b) shows the current distribution on the different input signal's phase at the center frequency of $2.10 \mathrm{GHz}$. It can be seen that the current flowing toward the left side becomes strongest at $t=0$. Then, the current flowing toward the right side becomes stronger and they nullify each other at $t=T / 4$. After that, current starts to flow toward the right side of the antenna providing the peak

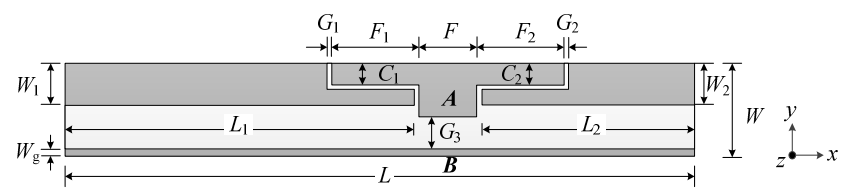

Fig. 8. Structure of the proposed capacitively coupled antenna.

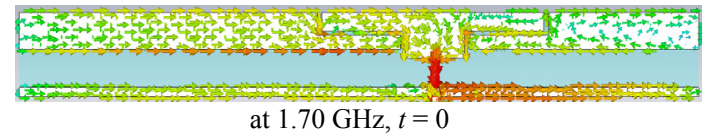

(a)

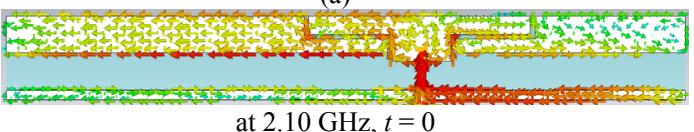

at $2.10 \mathrm{GHz}, t=0$

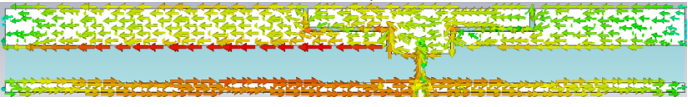

at $2.10 \mathrm{GHz}, t=T / 4$

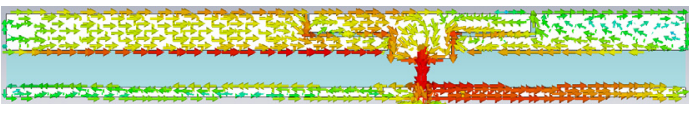

at $2.10 \mathrm{GHz}, t=T / 2$

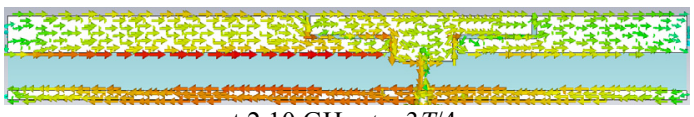

at $2.10 \mathrm{GHz}, t=3 T / 4$

(b)

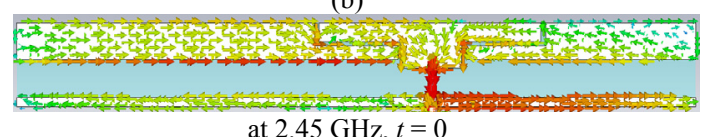

(c)

Fig. 9. Surface current density of the proposed antenna when excited at $1.7 \mathrm{GHz}, 2.1 \mathrm{GHz}$, and $2.45 \mathrm{GHz}$.

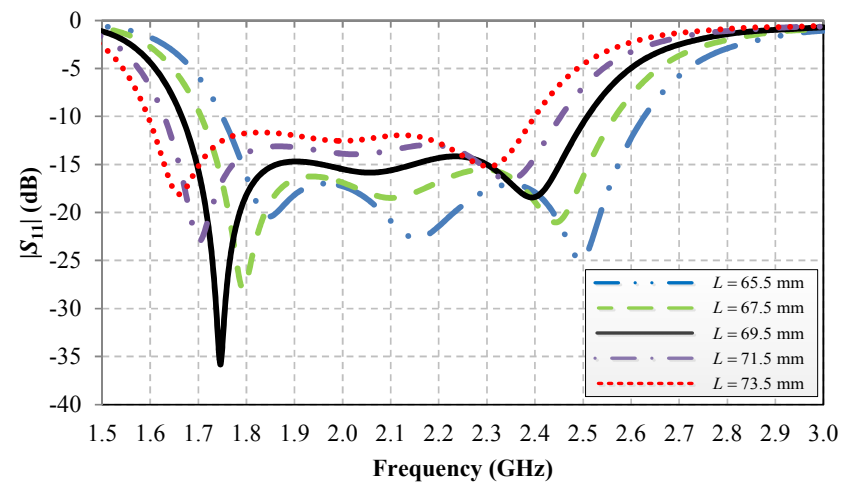

Fig. 10. $\left|S_{11}\right|$ of the proposed antenna when $L$ is varied.

at around $t=T / 2$. The current flowing toward the left side begins to grow and creates a null at around $t=3 T / 4$. Hence, the proposed antenna generates the current that flows back and forth along the wide side of the antenna similar to an operation of a dipole antenna.

Figure 10 shows the effect of the total length of the antenna on reflection coefficient. It can be seen that an increase in $L$ shifts the entire frequency band of the antenna toward the lower frequency and vice versa. The antenna length of $L=69.5 \mathrm{~mm}$ is chosen, due to the fact that the operating band covers both interested bands.

Figure 11 shows the relationship between the length of the long arm and the reflection coefficient of the antenna. As can be seen, the variation of $L_{1}$ significantly affects the lower band of the antenna. This result is consistent with the concept of antenna design, since the long arm creates the main resonance at the lowest part of the entire frequency band. The arm length of $L_{1}=39 \mathrm{~mm}$ is chosen, since it provides the best impedance matching at 
the resonance frequency together with the desired cutoff frequency at $1.7 \mathrm{GHz}$.

Figure 12 presents an influence of the short arm length. As can be seen from the current distribution, the short arm directly affects the high resonance frequency. Hence, the arm length $\left(L_{2}\right)$ is varied in order to find the suitable impedance bandwidth coverage at high frequency range. As a result, the arm length of $L_{2}=23.5 \mathrm{~mm}$ is chosen because it provides cutoff frequency at $2.5 \mathrm{GHz}$.

The effect from the width of the ground strip to the impedance matching of the proposed antenna is shown in Fig. 13. It can be seen that $W_{\mathrm{g}}$ significantly affects the resonance at low frequency range. The result of the parametric study demonstrates that the ground strip width of $W_{\mathrm{g}}=1 \mathrm{~mm}$ yields the best resonance matching at low frequency range while maintaining the impedance matching on the higher frequency band.

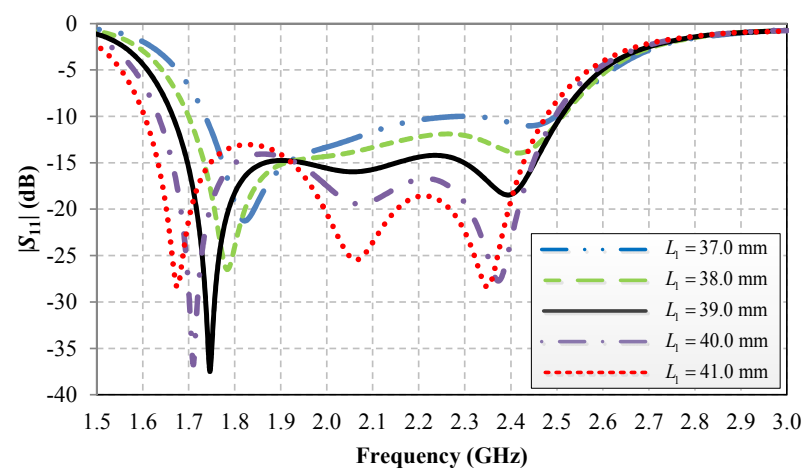

Fig. 11. $\left|S_{11}\right|$ of the proposed antenna when $L_{1}$ is varied.

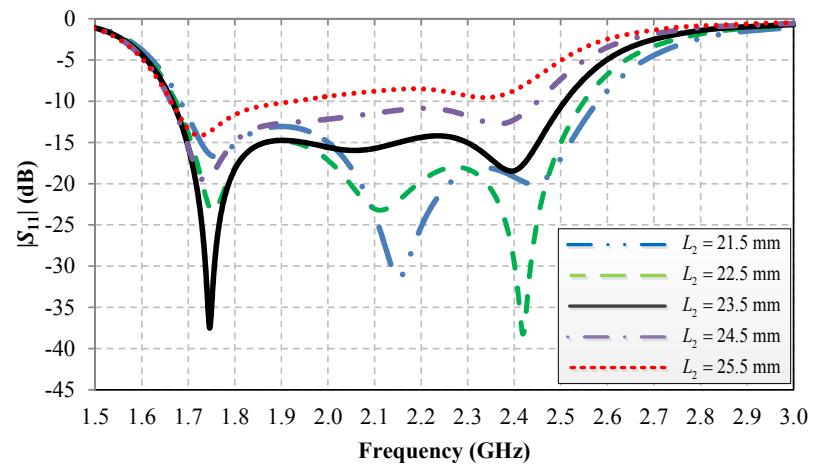

Fig. 12. $\left|S_{11}\right|$ of the proposed antenna when $L_{2}$ is varied.

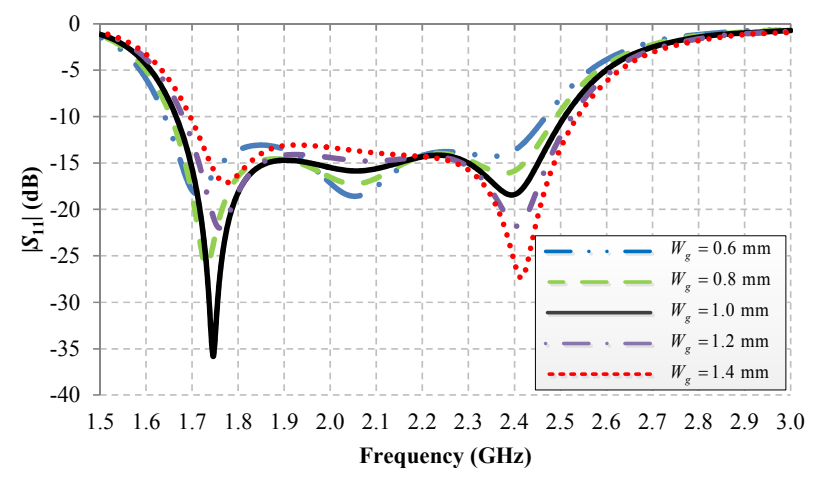

Fig. 13. $\left|S_{11}\right|$ of the proposed antenna when $W_{\mathrm{g}}$ is varied.
Figure 14 reveals an effect of the long radiating arm width toward the reflection coefficient of the proposed antenna. It can be seen that the long radiating arm width thinner than $4.0 \mathrm{~mm}$ leads to poor impedance matching on the entire frequency band. Nevertheless, the long radiating arm width thicker than $4.0 \mathrm{~mm}$ affects the overall size of the antenna. Thus, the long radiating arm width of $W_{1}=4.0 \mathrm{~mm}$ is selected.

The effect of changing the arm width on reflection coefficient of the antenna is shown in Fig. 15. There is not any significant change in bandwidth and resonance frequency, when width of the arm is adjusted. Hence, the arm width of $W_{2}=4.0 \mathrm{~mm}$ is picked, because that leaves the capacitive arm width with more than $1.5 \mathrm{~mm}$ size which can be easily fabricated.

The impact of the gap between the feeding patch and the long arm on the impedance matching is presented

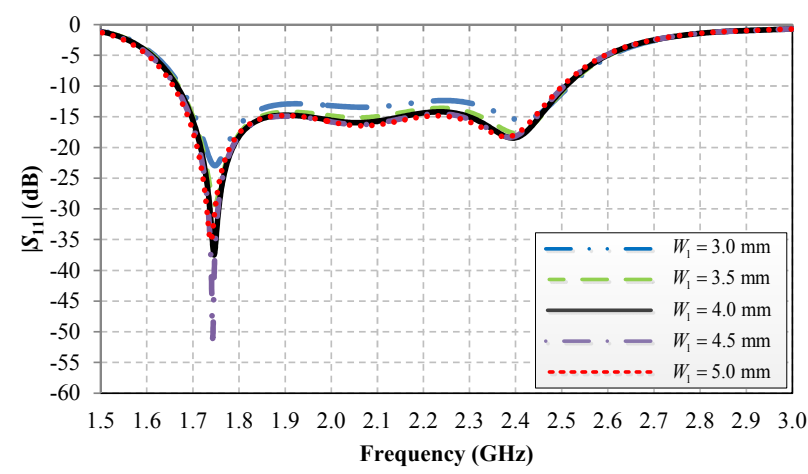

Fig. 14. $\left|S_{11}\right|$ of the proposed antenna when $W_{1}$ is varied.

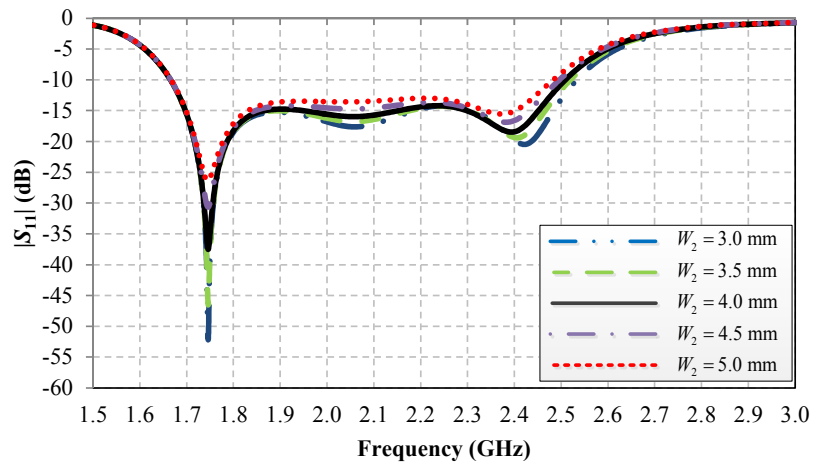

Fig. 15. $\left|S_{11}\right|$ of the proposed antenna when $W_{2}$ is varied.

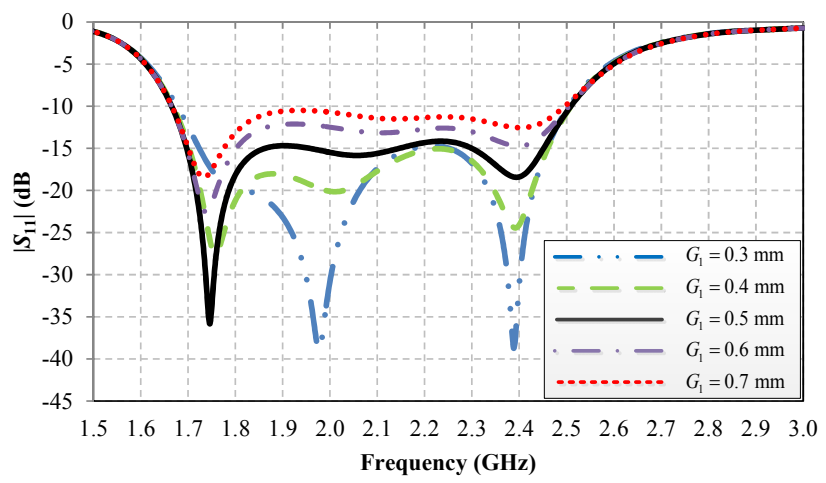

Fig. 16. $\left|S_{11}\right|$ of the proposed antenna when $G_{1}$ is varied. 
in Fig. 16. The simulation result shows that smaller gap size provides better impedance matching at the low resonance frequency. Nevertheless, an actual size of the gap is limited by the fabrication process. Therefore, the gap size of $G_{1}=0.5 \mathrm{~mm}$ is chosen.

Figure 17 displays the influence from gap between feeding patch and the short arm. It can be seen that the gap size of $G_{2}$ higher than $0.5 \mathrm{~mm}$ results in worse impedance matching around $2.3 \mathrm{GHz}$. However, the gap size of less than $0.5 \mathrm{~mm}$ results in lower bandwidth. Hence, the gap size of $G_{2}=0.5 \mathrm{~mm}$ is picked.

Figure 18 indicates the effect of the gap size between the feeding patch and the ground strip. Normally, dipole based antenna structure should have as small gap as possible in order to create uniform current distribution. However, the folded dipole structure needs none uniform current distribution. Hence, the gap size of $G_{3}=4.0 \mathrm{~mm}$

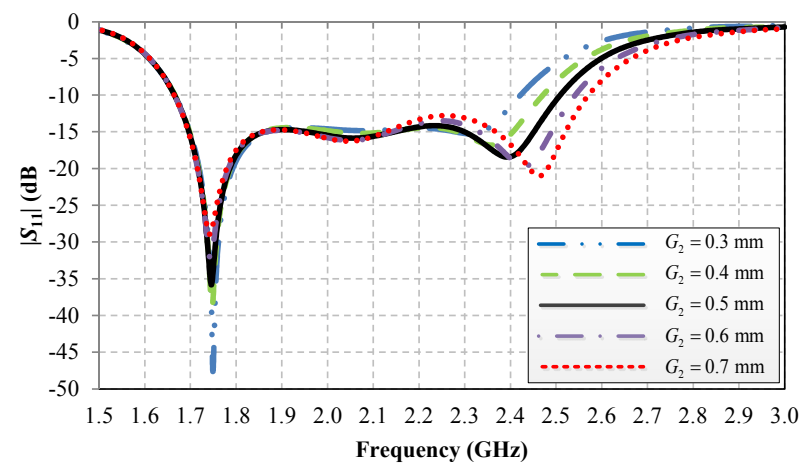

Fig. 17. $\left|S_{11}\right|$ of the proposed antenna when $G_{2}$ is varied.

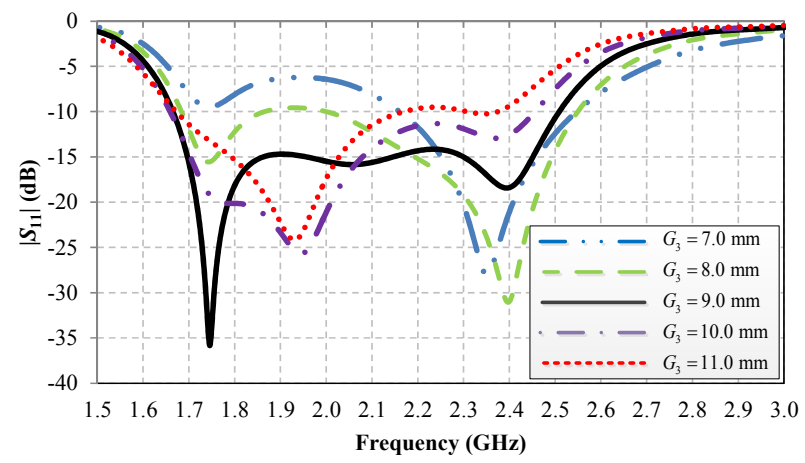

Fig. 18. $\left|S_{11}\right|$ of the proposed antenna when $G_{3}$ is varied.

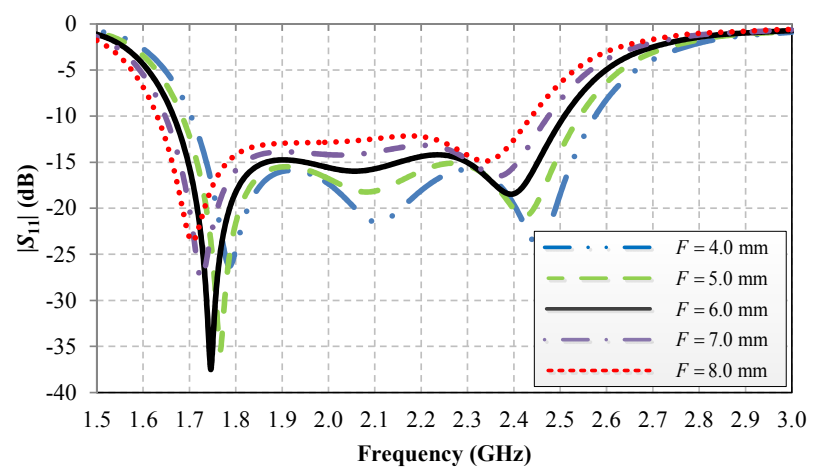

Fig. 19. $\left|S_{11}\right|$ of the proposed antenna when $F$ is varied. provides the best impedance matching on the interested frequency band.

Figure 19 shows the reflection coefficient of the proposed antenna with different feeding patch widths. Feeding patch width affects the overall size of the antenna. Thus, enlarging the feeding patch leads to a shift in frequency band toward the lower frequency and vice versa. The feeding patch size of $F=6 \mathrm{~mm}$ is selected, since it can be fabricated easily without too much increase in overall size of the antenna.

\section{Results and Discussion}

The computing results are simulated with finite integration technique in time domain (FIT-TD) using CST Microwave Studio. In order to provide the balance feeding, a sleeve balun is introduced into both simulation and the prototype antenna is shown in Fig. 20. The balun structure has a length of $35.7 \mathrm{~mm}$ which corresponds to the quarter wavelength of the center frequency at $2.1 \mathrm{GHz}$.

Figure 21 shows $\left|S_{11}\right|$ of the proposed antenna. The dashed line presents the simulated result, while the solid line shows the measured result. It can be seen that the proposed antenna has a bandwidth of $0.8 \mathrm{GHz}$ having an operating frequency range from $1.7 \mathrm{GHz}$ to $2.57 \mathrm{GHz}$. This leads to the antenna having an impedance bandwidth of $40.7 \%$

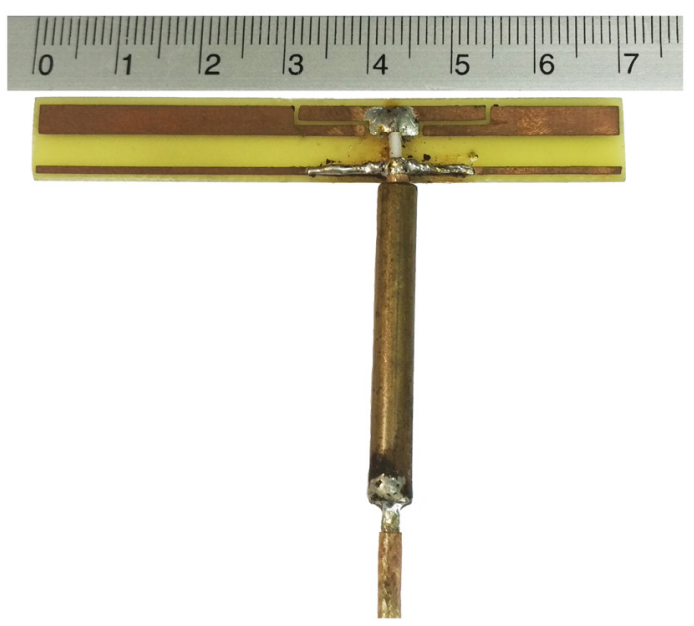

Fig. 20. Photograph of the prototype antenna.

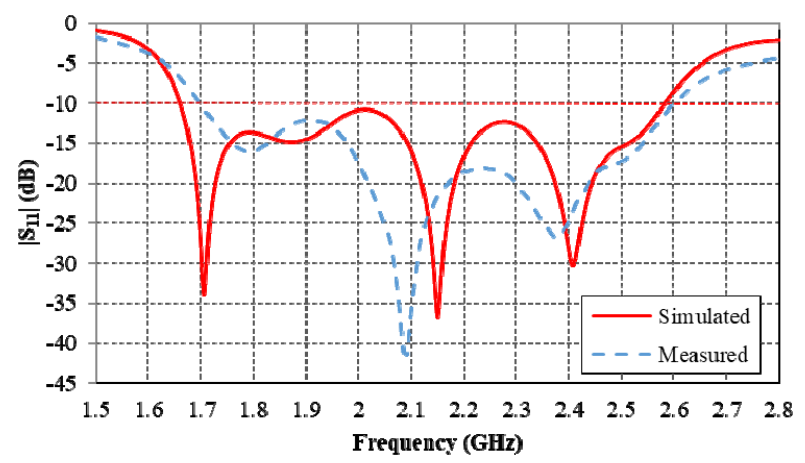

Fig. 21. Simulated and measured $\left|S_{11}\right|$ of the proposed antenna. 
(considering $\left|S_{11}\right|<-10 \mathrm{~dB}$ criteria). Therefore, the proposed antenna can operate in both $\mathrm{Wi}$-Fi band $(2.4 \mathrm{GHz}$ to $2.485 \mathrm{GHz}$ ) and $4 \mathrm{G}$ band (1.7 GHz to $2.2 \mathrm{GHz}$ ).

Figure 22 shows the gain of the proposed antenna. It can be seen that the proposed antenna has the gain higher than $1.47 \mathrm{dBi}$ throughout its operating bandwidth. The gain tends to be higher at the high frequency range. The proposed antenna radiates with the gain of $2.21 \mathrm{dBi}, 2.94 \mathrm{dBi}$, and $4.33 \mathrm{dBi}$ at $1.7 \mathrm{GHz}, 2.1 \mathrm{GHz}$, and $2.45 \mathrm{GHz}$, respectively.

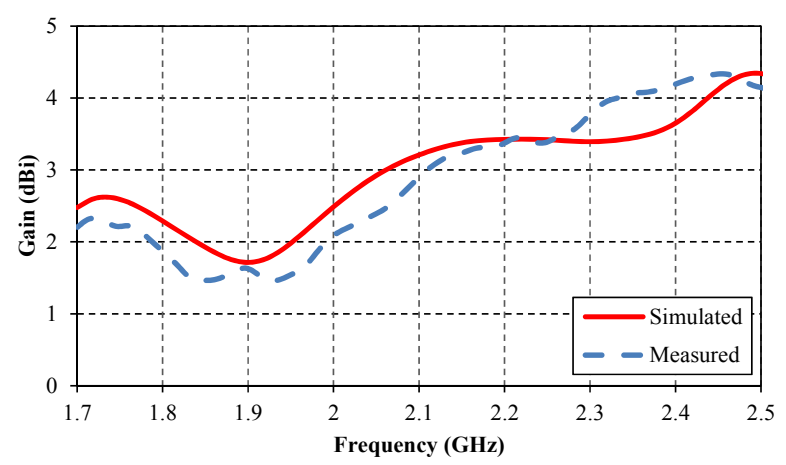

Fig. 22. Simulated and measured gain of the proposed antenna.

The radiation pattern of the proposed antenna is illustrated in Fig. 23. The solid line represents the simulated radiation pattern, while the dashed line shows the measured radiation pattern. The radiation pattern of the proposed antenna is unidirectional. The antenna was excited to radiate RF signal toward $\mathrm{Y}$-axis direction. The main lobe of the radiation pattern has a beam-width wider than $75^{\circ}$ on the $\phi$ direction and $180^{\circ}$ on the $\theta$ direction in the entire interested band. The radiating beam is a single polarized with a polarization dominant on $\mathrm{E}^{\phi}$ direction.

Since the simulation does not take the transmission line into an account, the measured radiation pattern on the back side of the antenna becomes significantly different from the simulation. However, the radiation pattern on the main lobe direction is similar to the computed result.

The comparison between performance of the proposed antenna and other antennas is shown in Tab. 1. Although, tablet antenna [21], [22] and mobile phone antenna [23-25] usually use $\left|S_{11}\right|<-6 \mathrm{~dB}$ as a criterion, their electrical size is still larger than the proposed antenna due to having a large ground structure. While both mobile antenna in [26] and standalone antenna in [27] use $\left|S_{11}\right|<-10 \mathrm{~dB}$ as a criterion, the antenna in [26] has a significantly larger size and the antenna in [27] has a very low bandwidth.

\section{Conclusions}

The proposed antenna is designed for Wi-Fi and $4 \mathrm{G}$ operation. It can easily be implemented in most kind of operating devices since it has a small size of $70 \mathrm{~mm} \times$ $9 \mathrm{~mm} \times 0.8 \mathrm{~mm}$ and does not require an external ground plane structure. The current distribution of the proposed

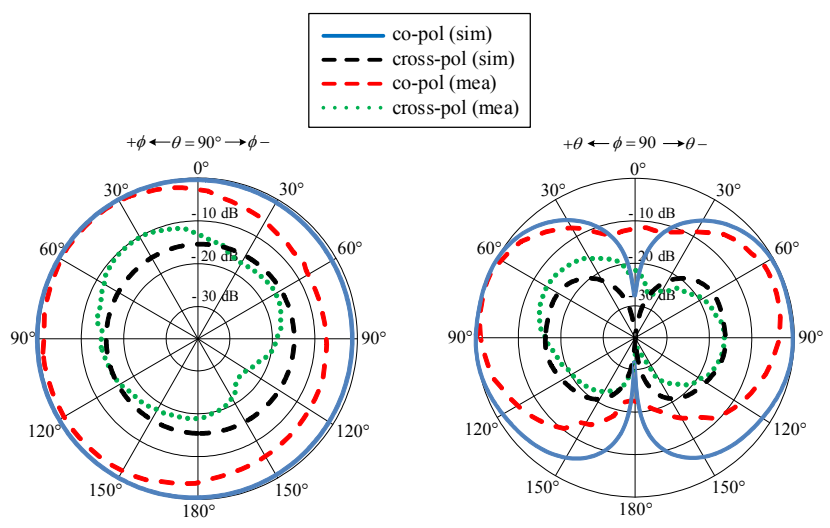

(a) H-plane at $1.70 \mathrm{GHz}$

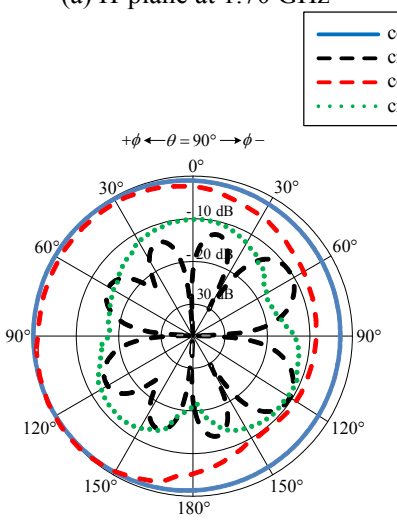

(c) H-plane at $2.10 \mathrm{GHz}$

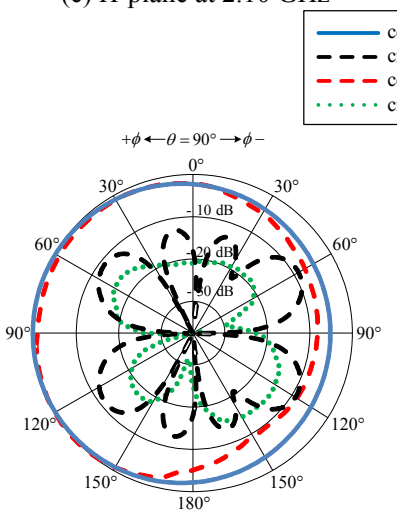

(e) H-plane at $2.45 \mathrm{GHz}$ (b) E-plane at $1.70 \mathrm{GHz}$
Fig. 23. Radiation pattern of the proposed antenna.

\begin{tabular}{|c|c|c|c|c|}
\hline & $\begin{array}{c}\text { Electrical Size } \\
(\text { at minimum frequency })\end{array}$ & $\begin{array}{c}\text { Frequency band } \\
(\mathrm{MHz})\end{array}$ & Bandwidth (\%) & Gain (dBi) \\
\hline Proposed & $0.4 \lambda \times 0.05 \lambda \times 0.005 \lambda$ & $1700-2570$ & $\begin{array}{c}40.70 \% \\
\left(\left|S_{11}\right|<-10 \mathrm{~dB}\right)\end{array}$ & $2.21-4.33$ \\
\hline$[21]$ & $0.47 \lambda \times 0.35 \lambda \times 0.001 \lambda$ & $\begin{array}{c}700-950 / \\
1700-2650\end{array}$ & $\begin{array}{c}30.3 \% / 43.7 \% \\
\left(\left|S_{11}\right|<-6 \mathrm{~dB}\right)\end{array}$ & $\mathrm{N} / \mathrm{A}$ \\
\hline$[22]$ & $0.55 \lambda \times 0.41 \lambda \times 0.014 \lambda$ & $\begin{array}{c}824-960 / \\
1710-2690\end{array}$ & $\begin{array}{c}15.2 \% / 44.5 \% \\
\left(\left|S_{11}\right|<-6 \mathrm{~dB}\right)\end{array}$ & $\mathrm{N} / \mathrm{A}$ \\
\hline$[23]$ & $0.35 \lambda \times 0.19 \lambda \times 0.002 \lambda$ & $\begin{array}{c}801-1002 / \\
1695-3000\end{array}$ & $\begin{array}{c}22.3 \% / 55.6 \% \\
\left(\left|S_{11}\right|<-6 \mathrm{~dB}\right)\end{array}$ & $0.7-3.4$ \\
\hline$[24]$ & $0.41 \lambda \times 0.21 \lambda \times 0.002 \lambda$ & $\begin{array}{c}824-960 / \\
1710-2690\end{array}$ & $\begin{array}{c}15.2 \% / 44.5 \% \\
\left(\left|S_{11}\right|<-6 \mathrm{~dB}\right)\end{array}$ & $0.98-5.1$ \\
\hline$[25]$ & $0.3 \lambda \times 0.15 \lambda \times 0.013 \lambda$ & $\begin{array}{c}760-1000 / \\
1550-2550\end{array}$ & $\begin{array}{c}27.3 \% / 48.8 \% \\
\left(\left|S_{11}\right|<-6 \mathrm{~dB}\right)\end{array}$ & $0.22-3.78$ \\
\hline$[26]$ & $0.78 \lambda \times 0.31 \lambda \times 0.051 \lambda$ & $2350-3250$ & $\begin{array}{r}32.1 \% \\
\left(\left|S_{11}\right|<-10 \mathrm{~dB}\right)\end{array}$ & $\mathrm{N} / \mathrm{A}$ \\
\hline$[27]$ & $0.23 \lambda \times 0.29 \lambda \times 0.009 \lambda$ & $\begin{array}{c}1750-1950 / \\
2340-2460\end{array}$ & $\begin{array}{c}10.8 \% / 5.0 \% \\
\left(\left|S_{11}\right|<-10 \mathrm{~dB}\right)\end{array}$ & 1.56 \\
\hline
\end{tabular}

Tab. 1. Comparison of antenna's characteristic between the proposed antenna and other related antennas. 
antenna is considered to determine the mechanism of the antenna. The parametric study of the antenna is carried out to identify the optimal parameters. Moreover, the antenna prototype was fabricated and tested. The antenna prototype has a coverage area of approximately 1 quadrant (more than $180^{\circ}$ in axis and more than $75^{\circ}$ in axis in the interested band) with a gain of $2.21 \mathrm{dBi}, 2.94 \mathrm{dBi}$, and $4.33 \mathrm{dBi}$ at $1.7 \mathrm{GHz}, 2.1 \mathrm{GHz}$ and $2.45 \mathrm{GHz}$, respectively. The radiation pattern of the proposed antenna is unidirectional and has a strong linear polarization in $\mathrm{E}^{\phi}$ direction.

\section{Acknowledgement}

This work is supported by the Faculty of Engineering, King Mongkut's Institute of Technology Ladkrabang under the contract number 2562-02-01-029.

\section{References}

[1] JAN, J. Y., HSIANG, C. Y. Wideband CPW-fed slot antenna for DCS, PCS, 3G and Bluetooth bands. Electronics Letters, 2006, vol. 42, no. 24, p. 1377-1378. DOI: 10.1049/el:20062750

[2] ZHOU, S., GUO, J., HUANG, Y., et al. Broadband dual frequency sleeve monopole antenna for DTV/GSM applications. Electronics Letters, 2009, vol. 45, no. 15, p. 766-768. DOI: 10.1049/el.2009.1040

[3] LEE, C. T., WONG, K. L. Broadband planar dipole antenna for DTV/GSM operation. Microwave and Optical Technology Letters, 2008, vol. 50, no. 7, p. 1900-1905. DOI: 10.1002/mop. 23500

[4] CHEN, H. D. Compact broadband microstrip-line-fed sleeve monopole antenna for DTV application and ground plane effect. IEEE Antennas and Wireless Propagation Letters, 2008, vol. 7, p. 497-500. DOI: 10.1109/LAWP.2008.2004213

[5] YEUM, I., PARK, J., KIM, J., et al. Compact and contact quadband (DVB-H UHF/L, WLAN $11 \mathrm{a} / \mathrm{b}$ ) antenna for PMP applications. Electronics Letters, 2010, vol. 46, no. 1, p. 11-13. DOI: $10.1049 / \mathrm{el} .2010 .2134$

[6] LEE, C. H., CHANG, Y. H., CHIOU, C. E. Design of multi-band $\mathrm{CPW}$-fed antenna for triple-frequency operation. Electronics Letters, 2012, vol. 48, no. 10, p. 543-545. DOI: $10.1049 / \mathrm{el} .2012 .0786$

[7] CHANG, T. H., KIANG, J. F. Compact multi-band H-shaped slot antenna. IEEE Transactions on Antennas and Propagation, 2013. vol. 61, no. 8, p. 4345-4349. DOI: 10.1109/TAP.2013.2262666

[8] BEHDAD, N., SARABANDI, K. A multiresonant single-element wideband slot antenna. IEEE Antennas and Wireless Propagation Letters, 2004, vol. 3, p. 5-8. DOI: 10.1109/LAWP.2004.825093

[9] ZHAO, A. P., RAHOLA, J. Quarter-wavelength wideband slot antenna for 3-5 GHz mobile applications. IEEE Antennas and Wireless Propagation Letters, 2005, vol. 4, p. 421-424. DOI: 10.1109/LAWP.2005.859382

[10] LUI, W. J., CHENG, C. H., ZHU, H. B. Compact frequency notched ultra-wideband fractal printed slot antenna. IEEE Microwave and Wireless Components Letters, 2006, vol. 16, no. 4, p. 224-226. DOI: 10.1109/LMWC.2006.872102

[11] SONG, Y., MODRO, J. C., WU, Z., et al. Miniature multiband and wideband 3-D slot loop antenna for mobile terminals. IEEE
Antennas and Wireless Propagation Letters, 2006, vol. 5, p. 148-151. DOI: 10.1109/LAWP.2006.874294

[12] DING, X., JACOB, A. F. CPW-fed slot antenna with wide radiating apertures. IEE Proceedings Microwaves, Antennas and Propagation, 1998, vol. 145, no. 1, p. 104-108. DOI: 10.1049/ipmap:19981629

[13] BHOBE, A. U., HOLlOWAY, C. L., PICKET-MAY, M., et al. Coplanar waveguide fed wideband slot antenna. Electronics Letters, 2000, vol. 36, no. 16, p. 1340-1342. DOI: 10.1049/el:20000984

[14] YANG J., KISHK, A. A novel low-profile compact directional ultra-wideband antenna: The self-grounded bow-tie antenna. IEEE Transactions on Antennas and Propagation, 2012, vol. 60, no. 3, p. 1214-1220. DOI: 10.1109/TAP.2011.2180317

[15] LODGE, O. Electric Telegraphy. U. S. Patent 609 154, 15 Aug., 1898.

[16] BROWN, G. H., WOODWARD, O. M. Experimentally determined radiation characteristics of conical and triangular antennas. RCA Review, 1952, vol. 13, p. 425-452.

[17] CARREL, R. The characteristic impedance of two infinite cones of arbitrary cross section. IRE Transactions on Antennas and Propagation, 1958, vol. 6, no. 2, p. 197-201. DOI: 10.1109/TAP.1958.1144578

[18] LeStARI, A. A., BHARATA, E., SUKSMONO, A. B., et al. A modified bow-tie antenna for improved pulse radiation. IEEE Transactions on Antennas and Propagation, 2010, vol. 58, no. 7, p. 2184-2192. DOI: 10.1109/TAP.2010.2048853

[19] ISBELL, D. Log periodic dipole array. IRE Transactions on Antennas and Propagation, 1960, vol. 8, no. 3, p. 260-267. DOI: 10.1109/TAP.1960.1144848

[20] CHEN, S. Y., WANG, P. H., HSU, P. Uniplanar log-periodic slot antenna fed by a CPW for UWB applications. IEEE Antennas and Wireless Propagation Letters, 2006, vol. 5, p. 256-259. DOI: 10.1109/LAWP.2006.873956

[21] CHEN, S.-C., HUANG, C.-C., CAI, W.-S. Integration of a lowprofile, long-term evolution/wireless wide area network monopole antenna into the metal frame of tablet computers. IEEE Transactions on Antennas and Propagation, 2017, vol. 65, no. 7, p. 3726-3731. DOI: 10.1109/TAP.2017.2700844

[22] WONG, K.-L., TSAI, C. Y. Half-loop frame antenna for the LTE metal-casing tablet device. IEEE Transactions on Antennas and Propagation, 2017, vol. 65, no. 1, p. 71-81. DOI: 10.1109/TAP.2016.2630716

[23] ZHANG, L.-W., BAN, Y.-L., SIM, C.-Y.-D., et al. Parallel dualloop antenna for WWAN/LTE metal-rimmed smartphone. IEEE Transactions on Antennas and Propagation, 2018, vol. 66, no. 3, p. 1217-1226. DOI: 10.1109/TAP.2018.2796724

[24] XU, Z.-Q., ZHOU, Q.-Q., BAN, Y.-L., et al. Hepta-band coupledfed loop antenna for LTE/WWAN unbroken metal-rimmed smartphone applications. IEEE Antennas and Wireless Propagation. Letters, 2018, vol. 17, no. 2, p. 311-314. DOI: 10.1109/LAWP.2017.2787863

[25] YANG, Y., ZHAO, Z., YANG, W., et al. Compact multimode monopole antenna for metal-rimmed mobile phones. IEEE Transactions on Antennas and Propagation, 2017, vol. 65, no. 5, p. 2297-2304. DOI: 10.1109/TAP.2017.2679059

[26] JA'AFREH, S. A., HUANG, Y., XING, L. Low profile and wideband planar inverted-F antenna with polarisation and pattern diversities. IET Microwave, Antenna and Propagation, 2016, vol. 10, no. 2, p. 152-161. DOI: 10.1049/iet-map.2015.0337

[27] SINGLA, N., RAJPUT, A. Compact dual-band metamaterialinspired antenna using SCSRR structures for mobile applications. In IEEE International Conference on Industrial and Information 
Systems. Roorkee (India), 2016, vol. 11, p. 614-617. DOI: 10.1109/ICIINFS.2016.8263012

\begin{abstract}
About the Authors ...
Sorana NIYAMANON received the Bachelor of Engineering (2010) in Electrical Engineering from Chulalongkorn University, Bangkok, Thailand, the Master of Engineering (2012) in Electrical and Electronic Engineering from Swansea University, Swansea, UK. He is pursuing the Doctor of Engineering in Electrical Engineering from King Mongkut's Institute of Technology Ladkrabang, Bangkok, Thailand.

Pisit JANPANGNGERN received the B.Eng. degrees from the Faculty of Engineering, Rajamangala University of Technology Thanyaburi (RMUTT), Pathum Thani, Thailand, in 2015 and the M.Eng. degree from the Faculty of Engineering, King Mongkut's Institute of Technology Ladkrabang (KMITL), Bangkok, Thailand in 2017, respectively. He is currently pursuing the D.Eng. degree and serves as a research assistant of Wireless Communication Laboratory at KMITL.
\end{abstract}

Chuwong PHONGCHAROENPANICH received the Bachelor of Engineering (Hons), Master of Engineering, and Doctor of Engineering degrees from the Faculty of Engineering, King Mongkut's Institute of Technology Ladkrabang (KMITL), Bangkok, Thailand, in 1996, 1998, and 2001, respectively. He is currently an Associate Professor at the Department of Telecommunications Engineering, KMITL where he also serves as the Leader of the Wireless Communication Laboratory at the same institute. He was the board committee of ECTI Association in 20082011. He serves as the chair of IEEE MTT/AP/ED Thailand chapter. He is the associate editor of IEICE Trans. Com. and ECTI Trans. EEC. He has been the organizing committee of several international conferences including the TPC chair of 2009 International Symposium on Antennas and Propagation (ISAP2009) and TPC member of ISAP2012. He is the reviewer of many journals including IEEE Trans. Antennas and Propagation and, Electronics Letters, ECTI Trans. and many international conferences including ISAP and Asia-Pacific Microwave Conference (APMC). His research interests are antenna design for various mobile and wireless communications, conformal antennas and array antenna theory. Dr. Phongcharoenpanich is a Member IEEE, IEICE and ECTI. 